\title{
CRESCIMENTO RELATIVO DO CAMARÃO MACROBRACHIUM AMAZONICUM PROVENIENTE DO RIO GRANDE, À JUSANTE DA USINA HIDRELÉTRICA DE ÁGUA VERMELHA, MINAS GERAIS
}

\author{
Carvalho, A.L.C. ${ }^{1,}$; Rodrigues, L.R. ${ }^{1}$; Costa, J.R.P. ${ }^{1}$; Nunes, J.S. ${ }^{1}$; Gomes, M.R.R.S. ${ }^{1}$; \\ Pantaleão, J.A.F. ${ }^{2} \&$ Andrade, L.S. ${ }^{1}$ \\ ${ }^{1}$ Universidade Federal do Triângulo Mineiro (UFTM), Campus Iturama, Grupo de Ensino, Pesquisa e Extensão \\ em Animais Aquáticos (GEPEAA). \\ ${ }^{2}$ Universidade Federal do Triângulo Mineiro (UFTM), Campus Uberaba, Grupo de Ensino, Pesquisa e Extensão \\ em Animais Aquáticos (GEPEAA). \\ *Autor correspondente: analaura.bio@hotmail.com
}

\begin{abstract}
Reservatórios são ambientes intermediários que podem influenciar nos aspectos ecológicos de diversas espécies que habitam o local. O camarão Macrobrachium amazonicum é uma espécie que apresenta hierarquia social, sendo que os indivíduos dominantes apresentam vantagens alimentícias, territoriais e reprodutivas. Investigações acerca do crescimento relativo desses animais permitem futuras inferências sobre a presença de morfotipos, dessa forma, objetivamos com este estudo avaliar o crescimento relativo M. amazonicum, provenientes da jusante da usina hidrelétrica de Água Vermelha no município de Iturama, Minas Gerais. Os espécimes foram coletados no período de outubro de 2017 a março de 2018, com a utilização de peneiras ensacadas e armadilhas próprias para camarão. Toda amostra foi conservada em álcool $70 \%$. No laboratório de microscopia da UFTM - Campus Iturama, foram mensurados o comprimento da carapaça (CC), comprimento do quelípodo direito (CQ), comprimento do própodo direito (CP) e comprimento total (CT) de cada indivíduo (machos e fêmeas). O crescimento relativo foi analisado observando crescimento de CQ, CP, CT em relação ao CC. Foram coletados 6.141 indivíduos. O CC das fêmeas variou de 1,1 a 19,8mm (média \pm desvio padrão $=7,55 \pm 3,44 \mathrm{~mm}$ ), enquanto os machos tinham de $2.1 \mathrm{a} 18.6 \mathrm{~mm} \mathrm{CC}(7,43 \mathrm{~mm} \pm 2,36)$. Os maiores tamanhos de CQ $(63,1 \mathrm{~mm})$, CT $(61,3 \mathrm{~mm})$ e CP $(23,8 \mathrm{~mm})$ foram encontrados em machos. O ajuste dos dados à uma regressão linear simples indicou uma relação positiva entre o comprimento da carapaça e todos os outros comprimentos analisados $(p<0,0001)$, ou seja, todas as relações morfométricas testadas apresentaram alometria positiva ( $b>0)$ e significativa (Teste $T ; p<0,001$ ), tanto para machos quanto para fêmeas. Futuros testes serão realizados a fim de estimar os tamanhos de maturidade sexual morfológica, testando se tais padrões se repetem entre as categorias etárias, bem como para investigar a presença de morfotipos nos machos da população estudada. As diferenças ecológicas do ambiente em razão da barragem, como disponibilidade de nutrientes, pode ser um fator explicativo para diferenças nos padrões morfométricos em relação a outras regiões. Tais dados nos permitem inferir sobre a intensa necessidade de conhecimento sobre o crescimento relativo, uma vez que a compreensão do assunto pode ajudar no desenvolvimento de estratégias de manejo que sejam compatíveis com suas características de crescimento, evitando a superexploração da espécie.
\end{abstract}

Palavras-chave: morfotipos, crescimento diferencial, camarão fantasma. 